\title{
BLENDED LEARNING E PROBLEM BASED LEARNING APLICADOS NO ENSINO DOS CONCEITOS DE SEGURANÇA DA INFORMAÇÃO
}

\author{
Bruno Anselmo Guilhen e Sérgio Takeo Kofuji \\ Laboratório de Sistemas Integráveis (PAD/LSI). Escola Politécnica da Universidade de São Paulo (USP) \\ Av. Prof. Luciano Gualberto, 380, Butantã - São Paulo - SP-Brasil
}

\begin{abstract}
RESUMO
A Segurança da Informação é uma disciplina do curso de nível médio técnico em informática e, devido à complexidade do conteúdo, este artigo propõe um método de aprendizado utilizando Blended Learning e Problem Based Learning para que os alunos tenham interesse e melhor aplicação teórico/prática do conteúdo. O método consiste na divisão do curso em duas etapas, na primeira etapa aplica-se Blended Learnig propondo a criação de um jogo envolvendo todo conteúdo da disciplina, juntamente com tarefas interativas, discussões e aplicação de tecnologia no ambiente de sala de aula. Na segunda etapa ocorre apenas o uso de tecnologia com aplicação do modelo de aula tradicional expositiva.
\end{abstract}

\section{PALAVRAS-CHAVE}

Blended Learning, Problem Based Learning, Segurança da Informação, Informática na Educação

\section{INTRODUÇÃ̃O}

O novo processo de ensinar aliado à imersão tecnológica vivida pela educação nos últimos anos criou a necessidade de definir parâmetros para os níveis de aprendizagem, bem como, uma mudança de conduta, de ações e pensamentos tanto do lado transmissor, quanto do lado receptor da informação. A maneira como os conteúdos são tratados em sala de aula, principalmente em disciplinas que exigem muitos outros conteúdos agregados, por exemplo, a disciplina de segurança da informação, que exige conhecimentos de redes de computadores, sistemas operacionais e programação precisa de uma reestruturação.

De acordo com Ferraz e Belhot (2010) essa reestruturação é o resultado de um processo de planejamento que está diretamente relacionado à escolha do conteúdo, de procedimentos, de atividades, de recursos disponíveis, de estratégias, de instrumentos de avaliação e da metodologia a ser adotada por um determinado período de tempo.

Parte dessa reestruturação envolve o uso das chamadas tecnologias educacionais. Segundo Herpich (2018), a aplicação de tecnologia no processo de ensino e aprendizagem é passiva de estimular as habilidades cognitivas dos estudantes, que são fatores determinantes para a construção do conhecimento.

$\mathrm{Na}$ rota de uso das tecnologias educacionais aplicadas em sala de aula, encontra-se o conceito de blended learning ou ensino híbrido e a metodologia PBL - Problem Based Learning também conhecida como metodologia baseada em problema que transforma o aluno de mero expectador para o agente do conhecimento. $\mathrm{O}$ aluno passa a ter um papel mais ativo no processo de aprendizagem, desenvolve projetos, resolve problemas e cria oportunidades para a construção do conhecimento. [Valente, 2014].

Esse artigo se propõe a avaliar o nível de aprendizagem em sala de aula, da disciplina segurança da informação presente no último semestre do curso técnico em informática, por meio de uma comparação entre a utilização de blended learning e $P B L$ em uma etapa do processo (primeira metade do semestre) e comparar os resultados com o método de ensino tradicional expositivo (segunda metade do semestre). 


\section{BLENDED LEARNING}

Blended learning ou ensino misto, segundo Bonk e Graham (2006) pode ser definido como um programa de educação formal que mescla momentos em que o aluno estuda os conteúdos e instruções usando recursos on-line, e outros em que o ensino ocorre em uma sala de aula, podendo interagir com outros alunos e com o professor.

De acordo com Valente (2014) ao utilizar blended learning a disciplina precisa ser estruturada para ter o conteúdo e as instruções elaborados especificamente para sua estrutura em vez de usar material avulso que pode ser acessado na internet. Além disso, a parte presencial deve necessariamente contar com a supervisão do professor, valorizar as interações interpessoais e ser complementar às atividades on-line, proporcionando um processo de ensino e de aprendizagem mais eficiente, interessante e personalizado.

Porém, Bloom e sua equipe descobriram que os principais fatores para estimular e desenvolver o processo cognitivo de aprendizagem estão pautados na estratégia utilizada, no estilo do ensino e na organização dos processos de aprendizagem, esses seriam os principais fatores que estimulariam o desenvolvimento cognitivo, mantendo as mesmas condições de ensino e ignorando fatores externos, Bloom cria a Taxonomia de Bloom e nela os alunos seriam muito mais estimulados e teriam melhores rendimentos no processo de aprendizagem.

O trabalho de Ferraz e Belhot (2010) mostra toda a evolução da taxonomia de Bloom e sua grande contribuição ao processo de aprendizagem, na figura 01 é possível perceber os processos conhecidos como Taxonomia dos Objetivos Cognitivos de Bloom que lista os seis objetivos para fazer com que o aluno caminhe pelo processo de aprendizagem, e a relação que cada nível possui nesse sistema.

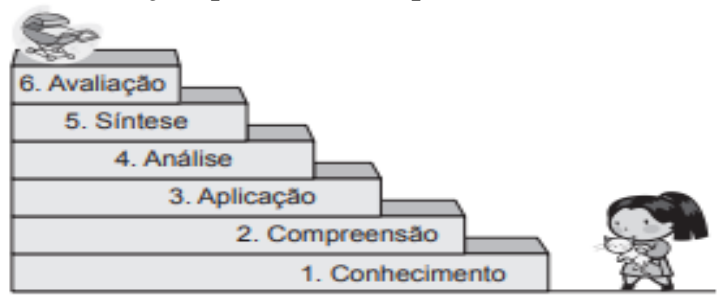

Figura 1. Categorias do domínio cognitivo proposto por Bloom

Do trabalho proposto por Bloom que surgiram as variações propostas para esse artigo, tais como o Blended Learnig e o Problem Based Learning e diversas outras metodologias de ensino discutidas na literatura educacional.

\subsection{Problem Based Learnig - PBL}

A construção do conhecimento, conforme proposto na Taxonomia de Bloom e mostrado na figura 01, sofreu evoluções e variações naturais com a chegada de novos métodos de processos de aprendizagem, por exemplo, o uso do computador e das tecnologias dentro do ambiente de sala de aula.

Assim, com o objetivo de ampliar o processo de aprendizagem em sala de aula surgiu na Universidade de Maastricht, processada nos cursos de medicina, o método PLB - Problem Based Learning, buscando estabelecer estratégia pedagógica de pesquisa e de raciocínio em que o aluno será levado a resolver problemas com o auxílio do professor. (Boud e Fletti, 1997).

Os alunos em sala serão divididos em pequenos grupos de trabalho e receberão a situação problema, em um primeiro momento eles precisarão identificar e entender o problema (fase de conhecimento), em seguida serão estimulados a debater entre os membros do grupo (fase da compreensão), depois partirão para a interpretação e busca de soluções possíveis (fase da aplicação e análise), por fim produzirão soluções possíveis e soluções alternativas (fase de síntese) até que o grupo apresente a melhor solução do problema proposto (fase de avaliação). (Barrows e Tamblyn, 1980).

Dentre as diversas vantagens apresentadas pelo método de Aprendizagem por Problemas (PBL) Barrows e Tamblyn destacam-se:

- $\quad$ Permite que o aluno busque o conhecimento de novos saberes.

- Estimula a criatividade e a imaginação na busca de soluções de problemas que ele ainda não tinha contato. 
- Estimula a capacidade de análise e tomada de decisão.

- Permite a integração e o trabalho em grupo.

Diante do cenário de metodologias de aprendizado propostas é possível comparar a metodologia tradicional de ensino, na qual o professor é o agente ativo do processo e o aluno o agente passivo e recebe exatamente aquilo que é enviado pelo professor com a metodologia PBL, em que o professor deixa de ser o centro do processo e cede esse lugar ao aluno, que será desafiado a buscar o conteúdo a ser aprendido, que precisa do conteúdo teórico para aplicar na solução de problemas. A figura 02 mostra um diagrama comparativo dos métodos. (Guzelis, 2006).

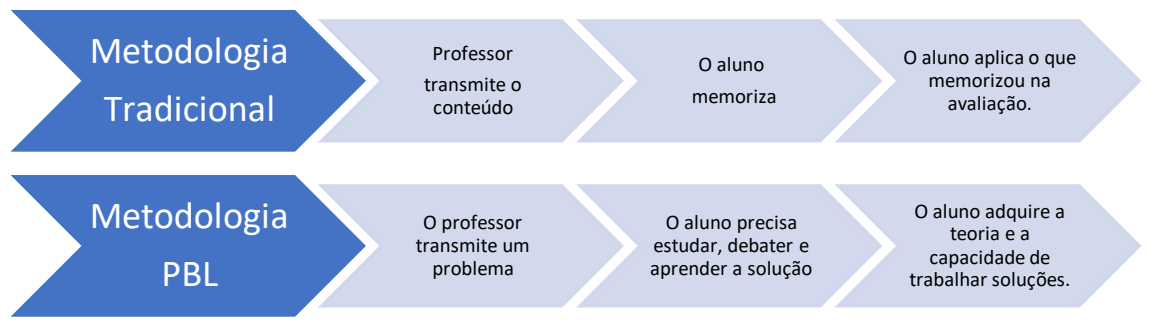

Figura 2. Comparação entre metodologia tradicional e PBL. Fonte: autor

A fusão do blended learning com PBL neste trabalho de pesquisa ocorre a partir do momento em que, na plataforma on-line do curso, todo material teórico da disciplina, os vídeos para revisão do conteúdo, as listas de exercícios e as regras para a criação de uma solução utilizando o conteúdo são disponibilizados. Assim, é proposto a cada grupo de alunos a construção de um jogo (situação problema), o jogo precisa utilizar os conceitos de segurança da informação, ele poderá ser construído utilizando cartas, tabuleiro ou mesmo digital (utilizando uma linguagem de programação qualquer). O professor oferece o suporte em sala, apresenta discussões sobre a estrutura teórica e auxilia na resposta dos questionamentos, nesse caso, segundo os preceitos de Valente (2014) configura-se o blended learning sendo utilizado por meio da resposta de uma situação problema, o PBL.

\section{METODOLOGIA}

A disciplina segurança da informação possui ementário complexo para alunos que estão finalizando o ensino médio técnico, além de possuir relação com os grupos mais importantes de disciplinas do curso, por exemplo, banco de dados, programação, redes, sistemas operacionais, a disciplina possui conteúdos diversos, como conceitos de criptografia, mecanismos de ataque, mecanismos de defesa, conceitos de elementos maliciosos (malwares), todos com um conjunto de definições que exigem do aluno dedicação e atenção.

$\mathrm{Na}$ busca para tornar a transmissão desses conteúdos o mais interessante possível, de forma que o aluno consiga reter o conteúdo teórico e prático, que se desenvolveu nesse trabalho de pesquisa, a disciplina conta com uma carga horária de uma hora e meia por semana, sempre no mesmo dia. As aulas sempre acontecem no laboratório de informática, os computadores são equipados com sistema operacional Windows 7 e Linux Ubuntu, acesso à Internet, diversos compiladores, softwares de desenvolvimento, plataformas de banco de dados, um sniffer (Wireshark) etc.

O problema da pesquisa consistia em saber se os conceitos de blended learning e $P B L$ podem exercer alguma influência no nível de interesse e aprendizagem dos alunos na disciplina em questão. Para criar os parâmetros de pesquisa, o experimento foi realizado nos anos de 2018 e 2019 em turmas do sétimo (e último) semestre do curso técnico em informática. Em 2018 a turma escolhida estudava no turno matutino e em 2019 no turno vespertino. Participaram do experimento 25 alunos em 2018 e 26 alunos em 2019, apenas um aluno não completou o processo, ele evadiu na segunda etapa de 2018.

$\mathrm{O}$ método criado consistiu em dividir o semestre em duas partes, na primeira aplicar blended learning e $P B L$, na segunda ministrar aula no método tradicional, popularmente conhecido como "voz e giz". O parâmetro para medição foram as notas de trabalhos, provas teóricas e empenho nas atividades práticas.

Inicialmente todo o material teórico e de revisão bibliográfica do curso foi disponibilizado no ambiente virtual do aluno (Moodle). Na primeira aula as regras foram criadas e estabelecidas com a turma e foram 
formados grupos de 2 ou no máximo 3 alunos.

Para aplicação do $P B L$ foi proposto que cada grupo criasse um jogo, que poderia ser digital (utilizando uma linguagem de programação qualquer) ou não digital (de tabuleiro, de cartas) desde que envolvesse a aplicação direta do conteúdo da disciplina, por exemplo, o jogo tinha que relacionar corretamente uma ação de ataque (Flooding) ou maliciosa (Vírus) com o correto mecanismo de defesa, seja ele firewall ou antivírus.

O professor exercia papel de mediador do conteúdo e durante os dois meses do prazo para a criação do jogo o aluno precisou responder, no Moodle, duas listas de exercícios que foram, posteriormente a resolução, discutidas em sala. Pouco conteúdo teórico foi ministrado, em sala de aula os alunos traziam as discussões e o professor dava as instruções fazendo com que os alunos caminhassem pelas categorias do domínio cognitivo proposto por Bloom, estudados por Ferraz e Belholt (2010) e mostrados na figura 1.

Nessa primeira etapa o aluno recebeu conteúdo teórico na plataforma virtual para estudar antecipadamente em casa, as listas de exercícios também foram inseridas na plataforma para que ele resolvesse fora do ambiente de sala de aula. Nos dois meses que compuseram a primeira etapa, a sala de aula foi utilizada para tirar dúvidas com o professor, propor discussões e realizar dinâmica de grupo sobre o conteúdo da disciplina e alinhar tudo isso ao jogo que cada grupo deveria criar, seguindo assim os conceitos de $P B L$ discutidos por Boud e Feletti (1997).

Para alimentar os alunos com conteúdo dinâmico foi proposto que eles assistissem quatro vídeos sobre segurança da informação presentes em Antispam (2019), bem como, utilizassem definições de segurança da Cartilha de Segurança para Internet (2012) ambos mantidos pelo Comitê Gestor da Internet no Brasil (CGI.BR).

A criação e apresentação do jogo era requisito obrigatório para realizar a prova escrita, neste caso, todos os grupos, de 2018 e 2019, apresentaram os projetos e foram habilitados para realizar a prova. No dia da prova, nos 45 minutos iniciais os alunos realizaram atividade avaliativa, composta por dez questões sobre o conteúdo, para compor a nota da prova. Essa atividade avaliativa era realizada no ambiente Socrative (2019), criava-se uma sala de aula, os grupos acessavam e realizavam as dez questões no tempo de 45 minutos. Os 45 minutos finais da aula eles realizavam a prova escrita, teórica, composta por 14 questões.

A segunda parte do curso, os dois meses e meio que restavam para terminar o semestre, a disciplina foi ministrada com o professor sendo o agente ativo do processo, método expositivo tradicional, sem nenhum conteúdo extra na plataforma, apenas aula expositiva e duas listas de exercícios. As aulas duravam uma hora e meia, o conteúdo era explicado e esquemas desenhados no quadro. $\mathrm{O}$ aluno precisava entregar duas listas de exercícios sobre o conteúdo antes de realizar a prova final, ou seja, ele não precisava realizar os exercícios antes da aula ou do conteúdo ministrado.

\section{RESULTADOS}

Na primeira etapa os alunos entregaram jogos muito criativos, o que mais ficou evidente foi o empenho dos alunos para a construção dos jogos. regras, cartilhas, manuais. Todos os jogos precisavam de um manual de instruções e um memorial dos conceitos aplicados, isso possibilitava que o aluno fizesse uma revisão teórica dos conceitos. Poucos erros grosseiros foram encontrados nas definições e os alunos realizaram muito bem a ligação das técnicas de defesa com os elementos maliciosos e de ataque.

As imagens a seguir são fotos e prints de tela retiradas no dia da apresentação dos trabalhos.

$\mathrm{Na}$ figura 3 o jogo foi desenvolvido em Python e relacionava conceitos e técnicas sobre confidencialidade, integridade, autenticidade, disponibilidade e não repúdio.

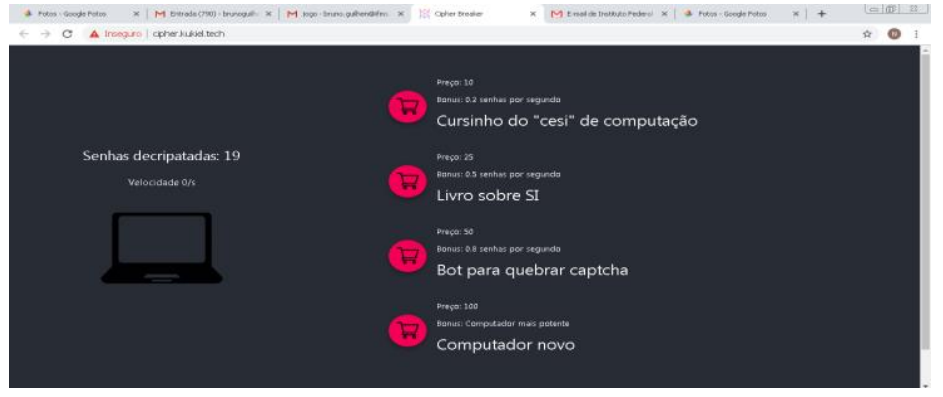

Figura 3. Tela do jogo sobre segurança em Python 
Na figura 4 a seguir o jogo construído foi um modelo de um jogo conhecido pelo nome de "War" em que territórios (ou computadores alvo) deveriam ser conquistados utilizando conceitos de vírus, trojan, antivírus, firewall.
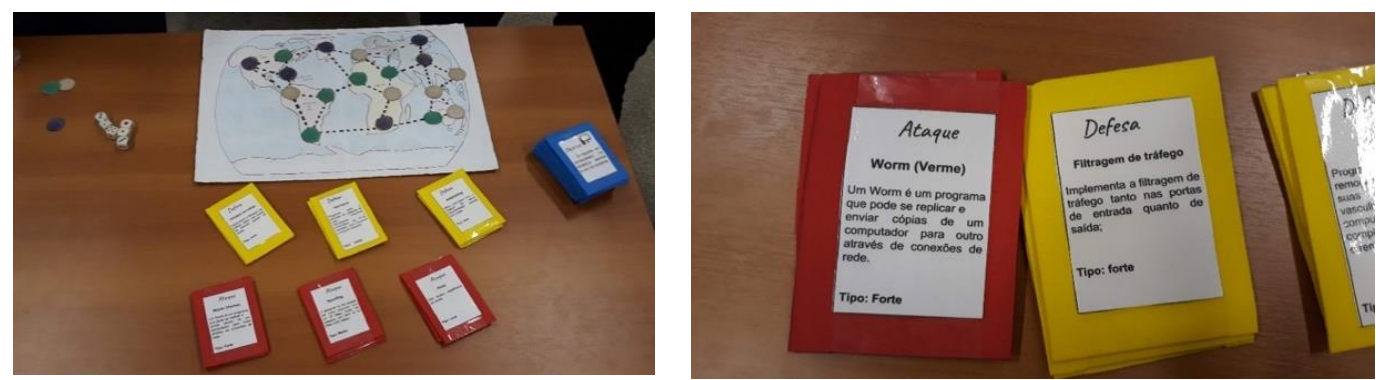

Figura 4. Jogo de tabuleiro, cartas e dados

Ao todo foram construídos doze jogos, de diversos padrões e modelos. Como um requisito básico era escrever um manual descritivo com as regras e definições a figura 5, a seguir, mostra as regras de um dos jogos criados.

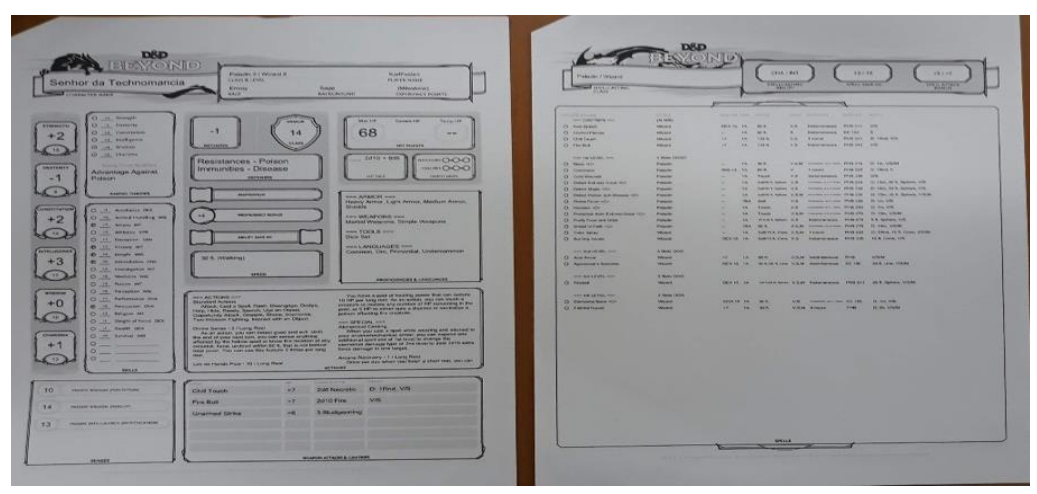

Figura 5. Manual descritivo com as regras e definições do jogo

Todo design, estrutura e regras propostas para o projeto foram pensadas pelos alunos, sem interferência do professor, nessa etapa o professor apenas solucionava dúvidas sobre os conceitos e sua aplicação.

Depois da entrega dos trabalhos, da resolução das listas os alunos estavam habilitados a realizarem a prova escrita, referente ao conteúdo que eles estudaram na construção do jogo.

No dia da prova escrita a primeira parte era realizada utilizando o Socrative (2019), os mesmos grupos que realizaram o trabalho entravam no site e na sala de aula criada para resolver de forma interativa, no computador ou celular, de dez a treze questões de múltipla escolha. A figura 6 mostra o resultado de uma etapa do Socrative com erros e acertos das questões.

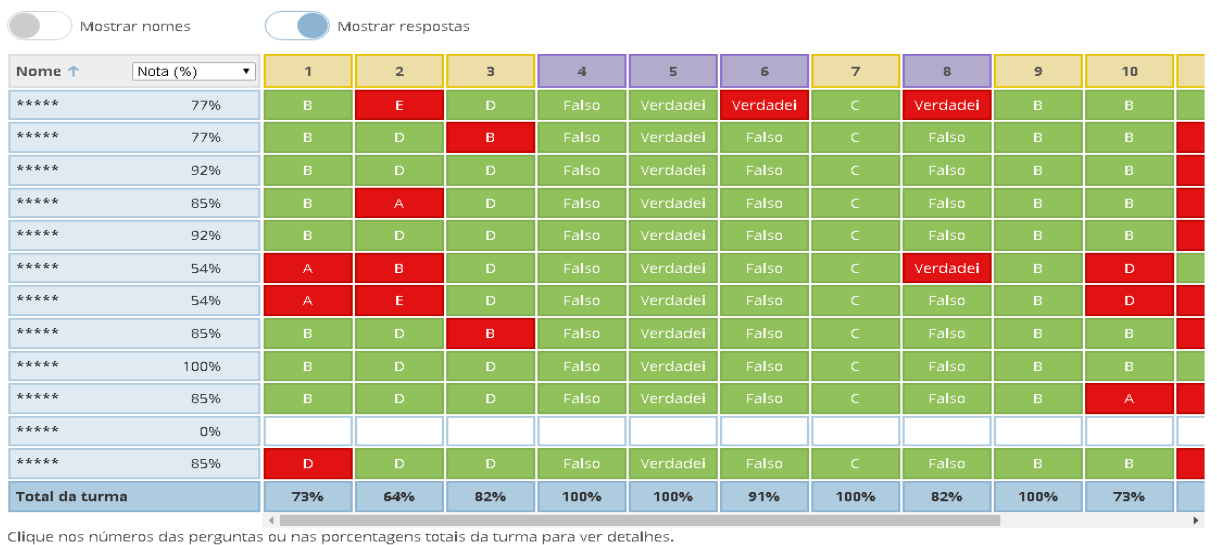

Figura 6. Resultado do questionário no Socrative 
Como já discutido anteriormente a segunda etapa do curso foi executada utilizando a metodologia tradicional, com aula expositiva, utilizando esquemas no quadro e listas de exercícios. Este cenário apresenta a metodologia tradicional na qual o professor transferia o conhecimento somente por meio de aula expositiva com listas de exercícios postadas no sistema do aluno.

No tópico a seguir os resultados do experimento são analisados.

\section{ANÁLISE DOS RESULTADOS}

Ao analisar os resultados percebe-se que a aplicação dos conceitos de blended learning e PBL fazem muita diferença no paradigma do aprendizado e dois reflexos imediatos foram constatados: o resultado das notas nas provas aplicadas e o nível de participação e interesse relacionado ao conteúdo. A primeira análise do experimento recai sobre as notas e o desempenho dos alunos na prova escrita, os gráficos ilustrados a seguir mostram a diferença de notas quando se aplicou o método e quando ele não foi aplicado.

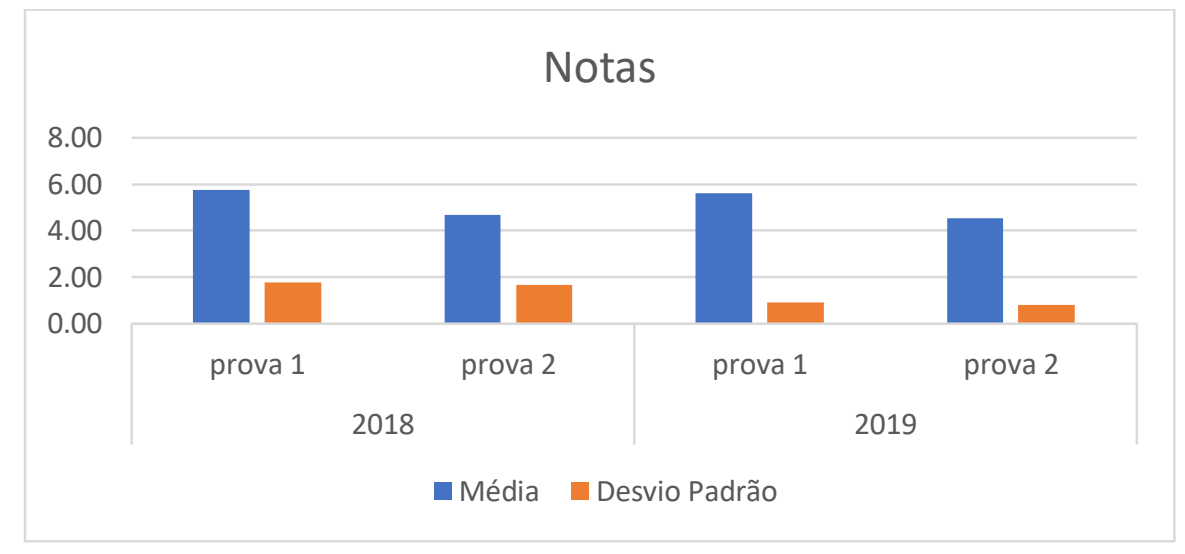

Figura 7. Notas dos alunos em 2018 e 2019

A prova tinha valor máximo de 7,0 (sete pontos). A prova 1 representa a aplicação do método e a prova 2 a aula expositiva tradicional. Neste caso, o que ficou evidente nos dois anos é que o desempenho cai sem a aplicação do método, a média da turma é menor na prova 2 e o comportamento é muito semelhante nos dois anos. O desvio padrão mostra um comportamento homogêneo nos dois anos e nas duas provas. No primeiro ano o desvio padrão foi maior devido a uma desistência que contou como nota zero. A queda do desvio padrão no ano de 2019 também pode ser associada a uma melhora na aplicação do método, aumento dos recursos de interatividade e experiência na aplicação, porém, as notas da turma tiveram comportamento muito similares mostrando homogeneidade do método.

A tabela 1 mostra os valores da média e do desvio padrão que foram utilizados para confecção do gráfico da figura 7. Com esses dados é possível comparar a proximidade da média da turma na prova 1 de 2018 com a prova 1 de 2019 e o mesmo comportamento pode ser observado com a prova 2 nos dois anos.

Tabela 1. Média e desvio padrão das notas das provas escritas

\begin{tabular}{|l|r|r|r|r|}
\hline & \multicolumn{2}{|c|}{2018} & \multicolumn{2}{c|}{2019} \\
\hline & prova 1 & prova 2 & prova 1 & prova 2 \\
\hline Média & 5,76 & 4,68 & 5,60 & 4,55 \\
\hline Desvio Padrão & 1,78 & 1,65 & 0,91 & 0,79 \\
\hline
\end{tabular}

Diante desses valores o que ficou evidente no ambiente de sala de aula foi o interesse do aluno quando submetido ao processo interativo e orbitando como elemento central, ao colocar o professor como fonte de apoio e expectador o aluno se interessou muito mais, participou e compartilhou muito mais conhecimento com os colegas. 
Ao analisar os dados da distribuição quartil, o que ficou evidente na pesquisa é que de fato o método que coloca o aluno como centro, que permite a solução por projetos por meio de um processo da construção do conhecimento possui real impacto no aprendizado, a distribuição do quartil mostrou que, na primeira avaliação em que o método estava sendo utilizado, 13 alunos atingiram a nota máxima (valor 7,0) no conjunto de provas em 2018. Já na segunda prova, nenhum aluno atingiu nota máxima, baseado na distribuição do quartil, os $25 \%$ melhores posicionados tiveram um rendimento pior. O mesmo comportamento aconteceu no ano seguinte, em 2019.

O gráfico da figura 7 mostra como o desempenho geral da turma cai tanto em 2018 quanto em 2019 sem a aplicação do método. A figura 8, mostra a distribuição por ano de aplicação do método e por prova e o comportamento de um ano para outro foi similar, observando que além da média geral das notas ser mais baixa sem o método, no geral os alunos rejeitam e regridem em desempenho. Nesse caso, infere-se que os bons alunos, bem como a maioria da turma, não se sentiram estimulados na segunda etapa do processo, na aplicação pura e simples do método tradicional, fazendo com que a aplicação de métodos de ensino se torne cada vez mais necessária, tais como o proposto.

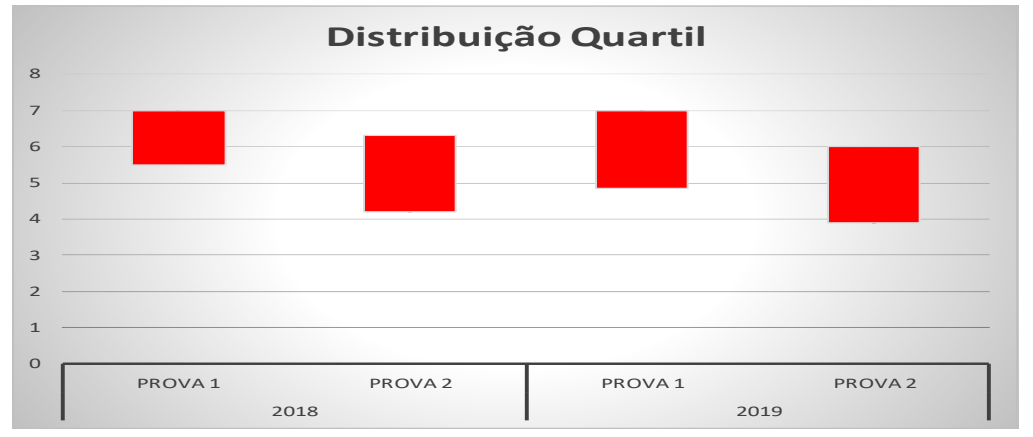

Figura 8. Gráfico da distribuição Quartil

No trabalho proposto por Bloom (1956) e Ferraz (2010) sobre as dimensões do processo cognitivo e dimensões do conhecimento, bem como, no trabalho de Staker e Horn (2019) que definem os parâmetros do blendend learning constatou-se que os alunos quando submetidos à tecnologia, porém sem estímulos corretos não reagiam ou demonstravam interesse, foi o que aconteceu nos resultados da prova 2. A aula expositiva acontecia no mesmo laboratório, com recursos computacionais e acesso à Internet, a diferença estava no estímulo do processo cognitivo e o resultado foi notas mais baixas e menos adesão às atividades propostas.

Outros dados foram analisados nesta pesquisa, por exemplo, a frequência em sala e evasão da disciplina, a opção por iniciar utilizando a inversão de sala de aula manteve os alunos em sala, a média da frequência ficou próxima de $94 \%$. Porém, ao iniciar o processo de aula expositiva ficou muito evidente o desinteresse, alguns alunos começaram a passar mais tempo navegando inutilmente na Internet do que se dedicando ao tema da aula.

Uma informação interessante que agrega valor ao método aplicado são feedbacks dos alunos que faziam estágio obrigatório em empresas no contraturno das aulas, alguns deles nas discussões com os colegas alegavam e repetiam frases do tipo:

- "No estágio eu já consigo entender na prática uma estrutura de Firewall" integridade".

"Eu apliquei criptografia e hash em arquivos para garantia de confidencialidade e

Esse tipo de feedback comprova que o aluno conseguiu externar o conteúdo trabalhado em sala de aula, levando a teoria construída por ele à prática.

\section{CONCLUSÕES}

A pesquisa não tem como objetivo destruir o processo de aprendizado tradicional, no qual o elemento ativo é a figura do professor, porém em uma disciplina com conteúdo amplo em conhecimento, volume e profundidade como é o caso de Segurança da Informação surge a necessidade de aliar a tecnologia com as melhores práticas de ensino. 
Foi possível observar que só a tecnologia não seria suficiente para gerar no aluno o interesse pelo conhecimento, para que ele simplesmente deixasse de "estudar para a prova" e passasse a um patamar de reter e aplicar o conjunto de informações tratados na disciplina.

Assim, verifica-se que o método aplicado, utilizando os conceitos de blended learning e sala de aula invertida, modificaram o interesse do aluno pela disciplina e consequentemente pelo conteúdo por ela tratado, fato que ficou evidenciado nas notas das provas e no comportamento em sala de aula.

Como proposta para trabalho futuro entende-se que esse método pode ser aplicado em disciplinas EAD, com um público heterogêneo, ou seja, qualquer estudante que queira aprender os conceitos de segurança da informação e esteja disposto a trabalhar na plataforma EAD. No ambiente EAD uma gameficação das atividades para prender e chamar a atenção do aluno também faz parte da proposta.

\section{AGRADECIMENTO}

Agradecimento especial ao projeto Erasmus e ao projeto EULA-GTEC.

\section{REFERÊNCIAS}

Antispam. (2019). Núcleo de Informação e Coordenação. Disponível em: 〈http://www.antispam.br/videos〉. Acesso em: junho de 2019.

Barrows, H. S., Tamblyn, R. M. Problem-Based Learning: An Approach to Medical Education. Springer Publishing Company. New York. 1980 - 224 p.

Bergmann, J.; Sams, A. (2012). Flip Your Classroom: reach every student in every class every day. Eugene, Oregon: ISTE, 2012.

Bloom, B. S. et al. (1956). Taxonomy of educational objectives. New York: David Mckay, 1956. 262 p. (v. 1).

Bloom, B. S.; Hastings, J. T.; Madaus, G. F. Handbook on formative and summative evaluation of student learning. New York: McGrawHill, 1971

Bonk, C. J., Graham, C. R. (2006). The Handbook of Blended Learning: Global Perspectives, Local Designs. Ed. Pfeiffer. San Francisco, CA.

Boud D., Feletti G. The Challenge of Problem-based Learning. London. Kogan Page. 2 ed. 1997.

Cartilha de Segurança para Internet. (2012). Página do Comitê Gestor da Internet no Brasil (CGI.BR). Disponível em: <http//cartilha.cert.br/livro>. Acessado em: junho de 2019.

Ferraz, A. P. C. M., Belhot, R. V. (2010). "Taxonomia de Bloom: revisão teórica e apresentação das adequações do instrumento para definição de objetivos instrucionais". In Gest. Prod., São Carlos, v. 17, n. 2, p. 421-431.

Guzelis, Cüneyt. (2006). An experience on problem based learning in an Engineering Faculty. Turkish Journal of Electrical Engineering and Computer Sciences. 14. 67-76.

Herpich, F., Bos, A. S., Kuhn, I., Guarese, R. L. M., Tarouco, L. M. R., Wives, L. K., Zaro, M. A. (2018).“Atividade cerebral no uso de recursos educacionais em realidade aumentada: uma análise da atenção do aprendiz". In VII Congresso Brasileiro de Informática na Educação (CBIE 2018). Anais do XXIX Simpósio Brasileiro de Informática na Educação (SBIE 2018). Pag 1858.

Socrative. (2019). Página Oficial do Aplicativo. Disponível em: 〈http://www.socrative.com〉. Acesso em: junho de 2019.

Staker, H.; Horn, M. B. (2019). Classifying K-12 blended learning. Mountain View, CA: Innosight Institute. Disponível em: <https://www.christenseninstitute.org/blog/5-blended-learning-myths-to-bust-in-2019/?_sft_topics=personalizedblended-learning>. Acesso em: junho de 2019.

Valente, J. A. (2014). Blended learning e as mudanças no ensino superior: a proposta da sala de aula invertida. Educar em Revista, Curitiba, Brasil, Edição Especial n. 4/2014, p. 79-97. Editora UFPR. 